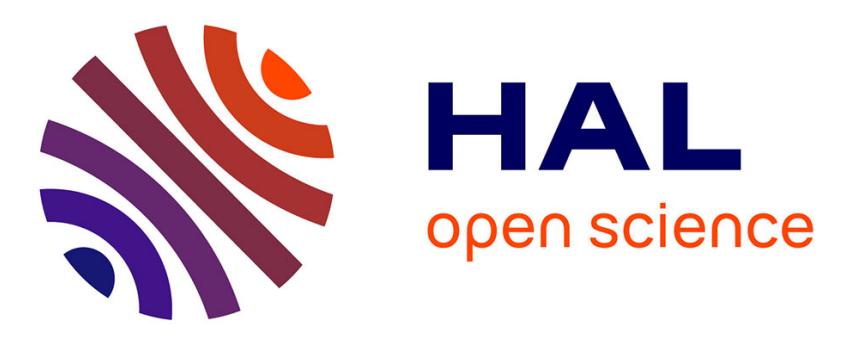

\title{
Fiber-optic sensor for long range displacement measurement of a rotating spindle
}

\author{
Zeina El Rawashdeh, Philippe Revel, Christine Prelle, Pierrick Letort, \\ Frédéric Lamarque
}

\section{- To cite this version:}

Zeina El Rawashdeh, Philippe Revel, Christine Prelle, Pierrick Letort, Frédéric Lamarque. Fiberoptic sensor for long range displacement measurement of a rotating spindle. 2016 11th France-Japan \& 9th Europe-Asia Congress on Mechatronics (MECATRONICS) /17th Internationall Conference on Research and Education in Mechatronics (REM), Jun 2016, Compiègne, France. pp.248-253. hal02120862

\section{HAL Id: hal-02120862 \\ https://hal.utc.fr/hal-02120862}

Submitted on 6 May 2019

HAL is a multi-disciplinary open access archive for the deposit and dissemination of scientific research documents, whether they are published or not. The documents may come from teaching and research institutions in France or abroad, or from public or private research centers.
L'archive ouverte pluridisciplinaire HAL, est destinée au dépôt et à la diffusion de documents scientifiques de niveau recherche, publiés ou non, émanant des établissements d'enseignement et de recherche français ou étrangers, des laboratoires publics ou privés. 


\title{
Fiber-Optic Sensor for Long Range Displacement Measurement of a Rotating Spindle
}

\author{
Zeina EL RAWASHDEH ${ }^{1}$, Philippe REVEL ${ }^{1}$, Christine PRELLE $^{1}$, Pierrick LETORT $^{2}$, Frédéric LAMARQUE ${ }^{1}$ \\ Sorbonne universités, Université de technologie de Compiègne, \\ CNRS, UMR 7337 Roberval, Centre de recherche Royallieu \\ CS 60319 - 60203 Compiègne cedex, France \\ Compiègne, France \\ CETIM-Centre techniques des industries mécaniques \\ CS 60300 Senlis, France \\ zeina.el-rawashdeh@utc.fr
}

\begin{abstract}
This paper presents the geometric design and the performances of a high precision fiber-optic linear displacement sensor. Its original characteristic is the ability to measure the linear displacement of a rotating spindle. This sensor consists of two fiber-optic probes and a grating of assembled cones. First, the measurement principle is introduced. Then, the geometric model for sizing the first prototype grating is presented. The high precision fabrication technique of this initial prototype is illustrated. Finally, the sensor was used to measure the linear displacement of a rotating spindle.
\end{abstract}

Keywords-fiber-optic; sensor; on-line; measurement; diamond tool machining.

\section{INTRODUCTION}

Nowadays the need of miniature sensors, with high performances, is becoming more and more essential in different industrial applications. Among these miniature sensors, are the displacement sensors, providing high accuracy on a long measurement range. These displacement sensors are mainly integrated in micro-positioning systems, where high resolution is required.

Displacement sensors based on optical technology are ones of the most adapted measurement systems, thanks to their ruggedness and often contactless characteristics. Optical interferometry is one of those technologies; they allow the measurement of linear displacements with resolutions and accuracies below the nanometer [1]. Fan et al. [2] developed a measurement system, consisting of a mini linear diffraction grating interferometer (LDGI), it has the dimensions of $50 \times 30 \times 30 \mathrm{~mm}^{3}$. The LDGI together with the focus probe are integrated into the spindle system of a micro-/nano Coordinate Measurement Machine (CMM). The measurement sensor delivers an accuracy of $30 \mathrm{~nm}$ over the $10 \mathrm{~mm}$ displacement range of the spindle. Another example is the study developed by Chung-Ping Chang et al [3], where the design of the conventional Fabry-Perot interferometer was modified in way, so that the attained measurement range was $100 \mathrm{~mm}$, the optical resolution was enhanced to a quarter wavelengths.

Several studies based on other optical technologies for linear displacement measurement have been done. CMOS technology is used to integrate optical metrology on a single chip. The result is a miniature interferometric linear encoder principle using diffraction grating [4]. Akihide Kimura et al. [5] described a three-axis surface encoder, consisting of a planar grating and an optical sensor head. It has been designed and manufactured for sub-nanometric displacement measurement along the $\mathrm{X}-\mathrm{,}, \mathrm{Y}-$ and $\mathrm{Z}$ directions. The optical sensor head had the dimension of $50 \mathrm{~mm}(X) \times 70 \mathrm{~mm}$ $(\mathrm{Y}) \times 40 \mathrm{~mm}(\mathrm{Z})$, it has been confirmed that the surface encoder could identify the vibration of the three-axis PZT stage with resolutions of better than $1 \mathrm{~nm}$ in all the three axes.

Besides the high performances for the developed sensor, the actual study has an additional objective which is the on-line displacement measurement of a rotating axis. This objective is useful for several applications. One of these is the on-line depth measurements for drilled holes. This application was the subject of many research studies. Koegl et al. [6, 7] presented a method to detect the depth of a laser-drilled hole in real time, using a breakthrough detector. It used magnetic field pickup coils placed upon the surface of a workpiece for the real-time detection of the magnetic field signal of laser-induced plasma during laser drilling. In more recent studies, Cheng-Hsiang Lin et al. [8] developed an optical measuring system based on confocal principle; this system is capable of real-time precision measurements of the depth of micro-holes during laser drilling with $0.5 \mu \mathrm{m}$ sensitivity. Chao-Ching Ho et al. [9] presented a novel method for monitoring and estimating the depth of a laser-drilled hole using machine vision; by transforming the laser-induced plasma region into a pixel value, a correlation could be obtained between the cumulative pixels and the hole depth.

The previous mentioned studies [6 - 9], are able to measure the on-line depth, only for laser-drilled holes, which can't be applied for all drilling process. However, the sensor developed in this research study, must be able to measure the on-line hole depth for mechanical drilling, when a conventional fabrication machining is in use.

In order to achieve the overall requirements for the actual 
measurement system fiber-optic technology was the one chosen for the developed sensor, thanks to its several advantages, like: the miniature size, immunity to electromagnetic interferences, its access in different environmental conditions, etc [10].

A miniature fiber-optic sensor able to provide a nanometric resolution over a millimetric range was proposed. In two previous studies, the principle of the sensor in one dimension and in two dimensions had been validated respectively [11, $12]$.

In this research study, the fiber-optic displacement sensor is used to measure the linear displacement of a rotating spindle. The measurement has to be independent of the angular orientation of the spindle axis during the linear movement. To satisfy the requirements of the target application, which is the on-line depth measurement for drilled-holes, the mirror must be axis-symmetrical, and consequently its surface has to be curved (convex).

In this paper, the measurement principle and the geometric model of the sensor reflector are introduced. Then, the fabrication technique is presented. Finally, the measurement principle of the sensor is validated experimentally.

\section{SENSOR PRINCIPLE}

The sensor consists of two fiber-optic probes and a high reflective mirror in relative displacement. Each probe has one emission fiber and four reception fibers; the reflected light detected by the sensor depends on the distance between the mirror and the probe. The sensor performances when it is associated to a flat surface have been already studied [13]. When translating the flat mirror perpendicularly to the probe axis, the sensor response curve is obtained. Figure 1 (a) shows the axial displacement of the mirror in front of the fiber optic probe, which generates the response curve shown in Figure 1 (b).

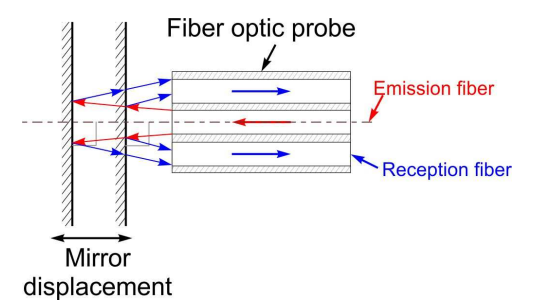

(a)

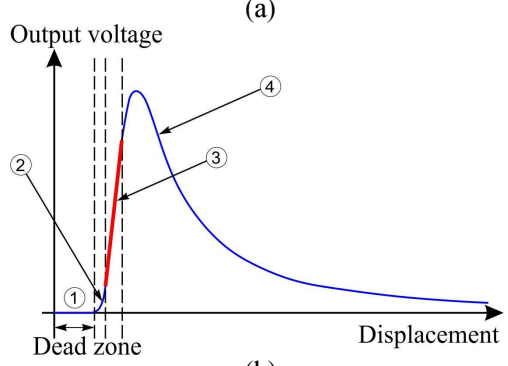

(b)

Fig. 1. Measurement principle of the fiber-optic displacement sensor.
The working zone for the sensor is zone 3 because of its linearity and high sensitivity. However, the measurement range of that zone, for the axial displacement is limited to 200 $\mu \mathrm{m}$, which is not suitable for applications requiring large strokes. For that reason, and in order to increase the linear measurement range, the displacement direction of the flat mirror is different from the normal vector orientation of its surface resulting in the multiplication of the nominal range value by the factor of $(\sin \varepsilon)^{-1}$; where $\varepsilon$ is the inclination angle related to the grating axis. As a result, the fiber-optic probe displaces laterally to the flat mirror. Two schematic diagrams for the displacement directions in the classical case (Figure 2 (a)) and the lateral case (Figure 2 (b)) are presented.

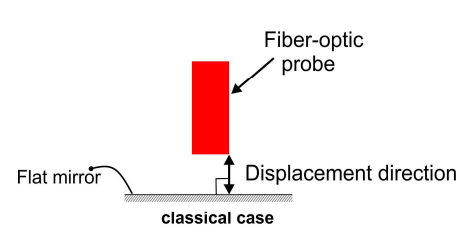

(a)

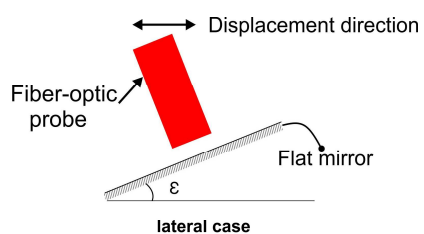

(b)
Fig. 2. Schematic diagrams for the displacement directions.

By repeating the tilting mirror configuration, a reflective grating is obtained.

In order to avoid the transition between two consecutive steps in the grating, two fiber-optic probes are used, which ensures a continuous displacement measurement over a long range.

In this research study, the objective is to measure the linear displacement of a rotating axis for that, the sensor reflective grating has to have a $3 \mathrm{D}$ shape in order to provide a valid measurement even if the sensor rotates along its axis of symmetry. A schematic diagram of this grating associated to the fiber-optic probes is shown in Figure 3.

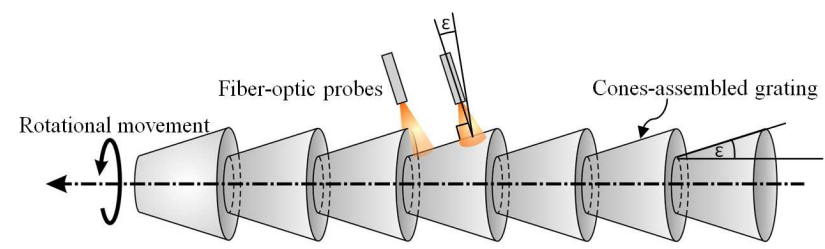

Fig. 3. Schematic diagram of the cones assembled grating associated to the fiber-optic probes.

\section{GEOMETRIC MODEL OF THE REFLECTIVE SURFACE}

\section{A. Convex surface model}

The reflective grating of the sensor is a set of assembled cones; this implies that the sensor reflective surface is convex. For that reason, a geometric model for the sensor when it is associated to a convex reflector was developed. This model calculates the light intensity detected by the sensor as a function of displacement $\left(\mathrm{d}_{0}\right)$ and the radius of curvature $\left(\mathrm{R}_{\mathrm{c}}\right)$, which helped in comparing the sensor performances in two types of reflectors (planar and convexe) [10]. Figure 4 represents the results of that model, already presented in [10], where the response curves of the sensor for several radii of 
curvature $\left(R_{c}\right)$ have been obtained as a function of the displacement $\left(\mathrm{d}_{0}\right)$.

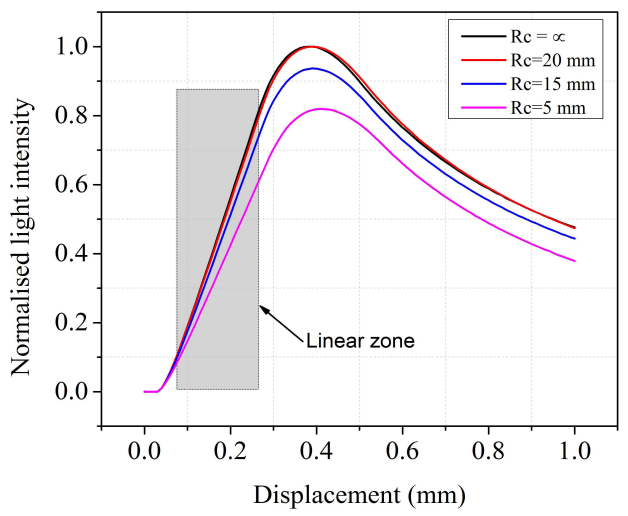

Fig. 4. Response curves for several radii of curvature.

The flat mirror configuration was used as a reference, where the light intensity is maximal. It is clear that the higher the radius of curvature is, higher will be the normalized light intensity detected in the linear part of the curve, which means higher sensitivity, and that enhances the sensor performance.

Figure 5 presents the variation of linear sensitivity with the radius of curvature $\left(R_{c}\right)$.

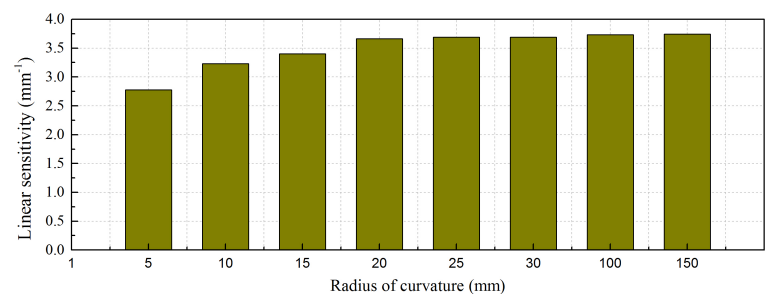

Fig. 5. Linear sensitivity for several radii of curvature (geometric model results).

It can be seen from Figure 5 that the highest linear sensitivity is obtained for the radii of curvature from $20 \mathrm{~mm}$ to $150 \mathrm{~mm}$. It has an approximate value of $3.75 \mathrm{~mm}^{-1}$. For the radii of curvature below $20 \mathrm{~mm}$, the linear sensitivity starts to decrease. For the small radii less than $10 \mathrm{~mm}$, the linear sensitivity reduces sharply.

\section{B. Experimental validation of the reflective surface model}

The geometric model previously described, has been experimentally validated. Two cylindrical pieces with different radii of curvature have been fabricated; piece (A) with radii of curvature $(20,15,10,5 \mathrm{~mm})$ and piece (B) with large radii of curvature $(27.5,25,20,17.5 \mathrm{~mm})$. The two pieces had been fabricated with a single crystal diamond tool, having a radius of curvature $(\mathrm{R}=2 \mathrm{~mm})$, on a high precision turning machine, which gave a surface roughness of $40 \mathrm{~nm}$, this roughness was measured with an interferometric microscope New View 200.

The calibration curve of the sensor, for each radius of curvature was obtained, except for $R_{c}=27.5 \mathrm{~mm}$ of piece (B) and $R_{c}=20 \mathrm{~mm}$ for piece (A) because of their higher roughness values due to the tool wear. Each fiber-optic probe has been moved away from each cylinder with a motorized translation stage. Figure 6 shows the experimental setup used in piece (A) and piece (B).

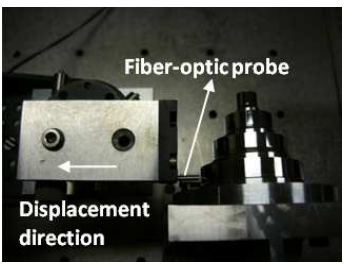

(a)

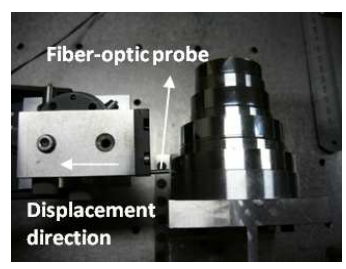

(b)
Fig. 6. Experimental setup: (a): piece (A), (b): piece (B).

The linear sensitivity has been calculated for each curve with $1 \%$ linearity criterion. Figure 7 shows the variation of the experimental linear sensitivity with the radius of curvature $\left(\mathrm{R}_{\mathrm{c}}\right)$.

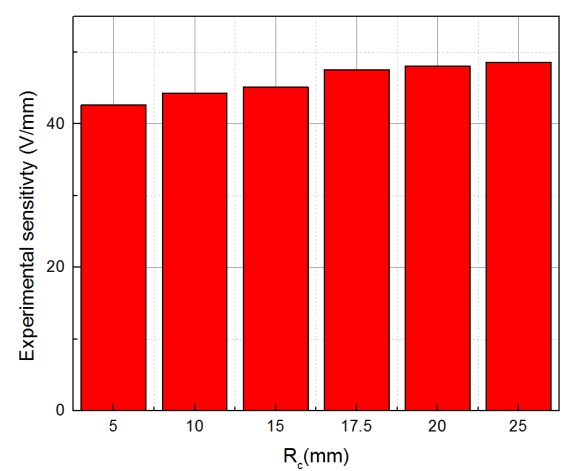

Fig. 7. Experimental sensitivity for several radii of curvature.

As seen from Figure 7, the experimental sensitivity increases as a function of the radius of curvature which is in agreement with the geometric model. For that reason, it is preferred to fabricate the cones assembled grating on a cylinder with a high radius of curvature, as that ensures the good performance of the fiber-optic sensor. In this study, a cylinder with a radius of curvature of $25 \mathrm{~mm}$ was the one chosen for the grating fabrication.

\section{Geometric design of the cones assembled grating}

A second geometric model was developed, for which the aim is to simulate the functionality of the sensor at long measurement range. This model provides the grating size, for which good performances are guaranteed. For that objective, two conditions are verified in this model:

1. The distance between the probe and the grating step has to be in the linear zone (zone 3 of figure 1).

2. The overlap between two successive signals is fixed at $30 \mu \mathrm{m}$ to avoid the linear measurement discontinuity during the steps transition. 
Figure 8 shows the geometric parameters considered for two steps in the cones assembled grating where:

- $\quad \mathrm{l}$ : the step length $(\mu \mathrm{m})$,

- $\mathrm{h}_{\mathrm{p}}$ : the step segment $(\mu \mathrm{m})$,

- $\varepsilon$ : the step angle $\left(^{\circ}\right)$,

- $\gamma$ : the angle at the bottom of the step $\left(^{\circ}\right)$.

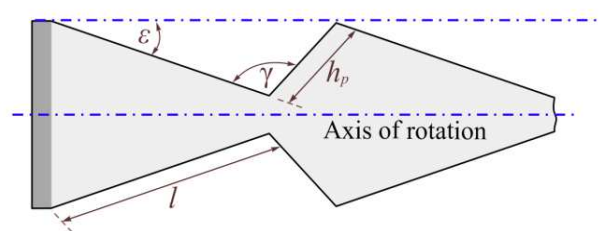

Fig. 8. Geometric form of two steps in the cones assembled grating.

For this initial prototype grating, the obtained geometric dimensions for each step are:

- $\quad$ Step length (1): $1541 \mu \mathrm{m}$

- $\quad$ Segment $\left(\mathrm{h}_{\mathrm{p}}\right): 253 \mu \mathrm{m}$

- Angle $(\gamma): 130^{\circ}$

- Step angle $\varepsilon: 7.17^{\circ}$

The geometric model gives the result shown in the figure below, where:

- Theoretical axial position $(\mu \mathrm{m})$ : the position of the sensor in the classical case (without inclination)

- Theoretical lateral position $(\mu \mathrm{m})$ : the position of the sensor in the lateral case (with inclination)

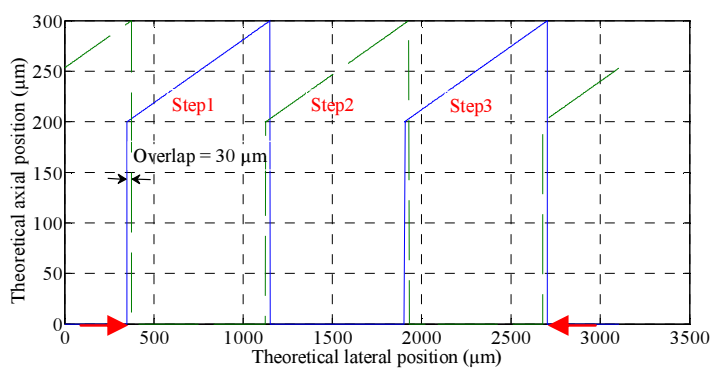

Fig. 9. Geometric model result for the cones grating sizing.

As seen from Figure 9, the lateral configuration for the sensor could extend the measurement range to $2.4 \mathrm{~mm}$ which corresponds to the linear parts of the three steps of the cones assembled grating. The overlap between two consecutive steps is $30 \mu \mathrm{m}$.

\section{CONES ASSEMBLED GRATING FABRICATION AND SURFACE CHARACTERISATION}

The cones assembled grating had been fabricated on a high precision turning machine and a single-crystal diamond tool having a radius of curvature $(\mathrm{R}=0.1 \mathrm{~mm})$ on an aluminium alloy which provided high geometrical precisions and good surface qualities $[14,15]$.

\section{A. Machining Process}

For the prototype considered in this study, ten steps were machined for the cones assembled grating.

The machining procedure is divided into two main parts; for the first part, every step is machined by achieving seven successive cuts. The second part is the last finishing cut which allows getting the final form of the overall grating. Figure 10 presents a schematic diagram for the cuts on one step of the grating; where for every step two successive trajectories were programmed: Firstly, from point A to point B in order to get into the material and to generate a slope respecting the value of the angle $\varepsilon$. The second trajectory is from point B to point $\mathrm{C}$ to get out from the material following the angle $\gamma$. Afterwards, the tool turns back to its initial position A to re-do another cut.

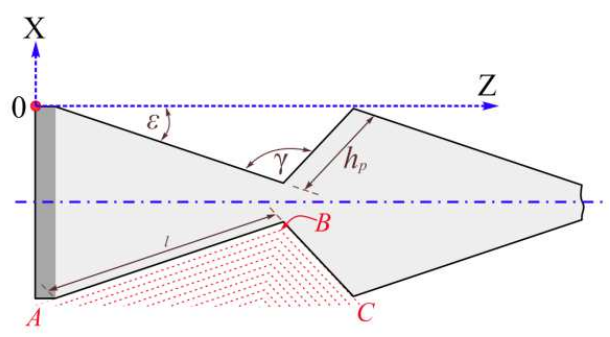

Fig. 10. Schematic diagram for the machining technique.

For the first six cuts, the depth of cut was fixed to $20 \mu \mathrm{m}$. The seventh cut was done at $10 \mu \mathrm{m}$. and the depth of the last finishing cut (the $8^{\text {th }}$ ) was fixed at $5 \mu \mathrm{m}$ which ensures optimal cutting conditions.

\section{B. Geometric and surface charcteristics of the fabricated assembled cones grating}

The resulted fabricated grating have been characterised geometrically using the Nanofocus ${ }^{\mathrm{TM}} \mu$ scan optical profilometer to measure the resulted dimensions after fabrication, the measurement axis of the profilometer is perpendicular to the translation axis of the grating (Figure 11).

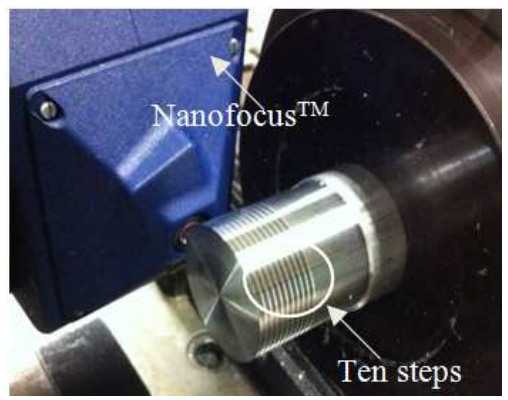

Fig. 11. Geometric characteristics with the Nanofocus ${ }^{\mathrm{TM}}$.

Figure 12 shows the profile of the measured grating. The average value of the angle $\varepsilon$ on the ten steps is $\left(7.25 \pm 0.01^{\circ}\right)$, for a theoretical one of $7.17^{\circ}$. 


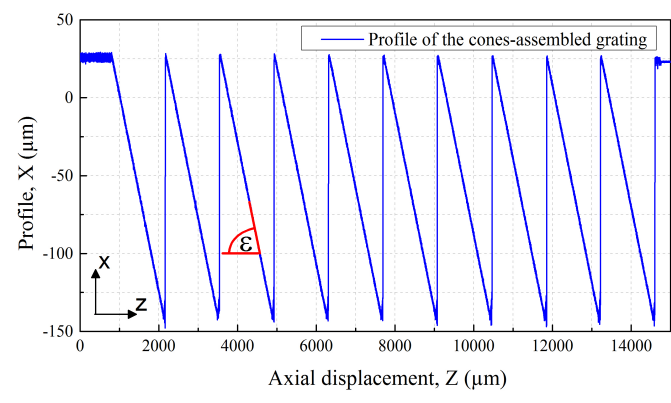

Fig. 12. Geometric profile of the cones assembled grating after fabrication.

The average value of the meausred step length on the ten steps is $(1539.6 \pm 4.1 \mu \mathrm{m})$, for a theoretical one of $1541.8 \mu \mathrm{m}$. The average value of the measured step height on the ten steps is $(196.2 \pm 2.1 \mu \mathrm{m})$, for a theoretical one of $194 \mu \mathrm{m}$. These results are good for a first prototype of the cones assembled grating. The surface roughness for each step in the conical grating were measured using the interferometric microscope New View 200, the averge measured roughness value on the ten steps is $(78.9 \pm 6.6 \mathrm{~nm})$, which is higher than the one obtained in the fabrication of the two cylindrical pieces (cf. III. $\mathrm{B})$. This difference is due to the radius of the fabrication tool $(\mathrm{R}=0.1 \mathrm{~mm})$, which was necessary to obtain the geometric characteristics of the conical grating. Figure 13 presents an example of the roughess value on the first step, $\left(\mathrm{R}_{\mathrm{a}}=0.079\right.$ $\mu \mathrm{m})$, this value is enough for high surface reflectivity.

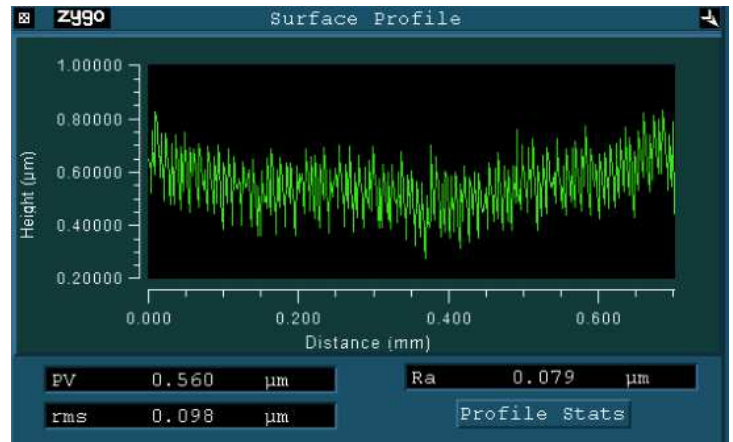

Fig. 13. Surface roughness for the first step using the interferometric microsocope New View 200.

\section{EXPERIMENTAL VALIDATION OF THE MEASUREMRNT PRINCIPLE FOR THE FIBER-OPTIC DISPLACEMENT SENSOR}

Once the surface characteristics have been identified, the measurement principle of the fiber-optic displacement sensor associated to the cones assembled grating was defined.

In order to validate the measurement principle using the initial prototype the conical grating was maintained on the high precision turning machine (in order to generate a translation and a rotational movement simultaneously). In addition, an experimental set-up guaranteeing the optimal positioning of the sensor in front of the conical grating was used.

For this initial prototype, one fiber-optic probe had been used for which, one signal was generated. The signal was duplicated and shifted in order to verify the overlap between the two successive signals. Figure 14 presents an example of the two signals. The grating moves at a speed of $0.5 \mathrm{~mm} / \mathrm{s}$ and an overlap of $30 \mu \mathrm{m}$ between the two signals was verified.

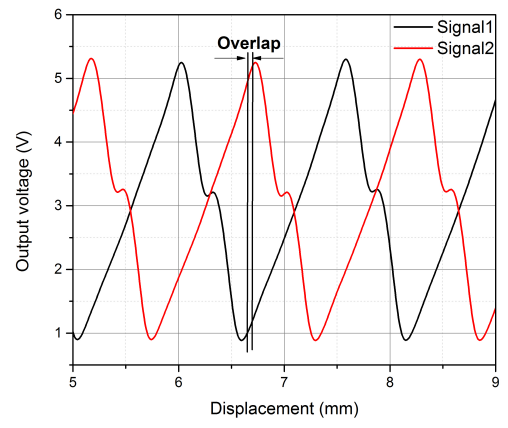

Fig. 14. Output voltage as a function of the grating displacement at $0.5 \mathrm{~mm} / \mathrm{s}$

As seen from the figure 14, the fiber-optic sensor measured the linear displacement on a measurement range of $2.4 \mathrm{~mm}$ on three steps of the cones grating, the average linear sensitivity is $4.57 \pm 0.06 \mathrm{~V} / \mathrm{mm}$ for a variation in the signal of $3.69 \mathrm{~V}$. As seen, the overlap in figure 14 is different from that in figure 9 , as the one presented in figure 14 is the experimental overlap and the one in figure 9 is the theoretical one.

In addition to the previous result, an axial displacement and a lateral one were done in front of one step in the conical grating (Figure 15).

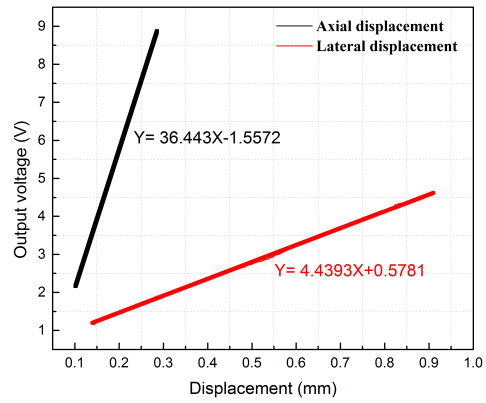

Fig. 15. Axial displacement and lateral displacement in front of one step in the cones assembled grating.

Figure 15 shows the difference between the axial and the lateral displacements; the axial sensitivity is $36.44 \mathrm{~V} / \mathrm{mm}$, whereas the lateral sensitivity is $4.44 \mathrm{~V} / \mathrm{mm}$. The axial measurement range is $184 \mu \mathrm{m}$, while the lateral one is 760 $\mu \mathrm{m}$. The inclination angle deducted is $6.99^{\circ}$.

In a second time, a translation movement associated to a rotational one was done. The grating was translated at a speed of $0.1 \mathrm{~mm} / \mathrm{s}$ and at the same time the spindle was rotated at 0.5 rps. The fiber-optic probe gave the following ouput voltage signal (Figure 16). 


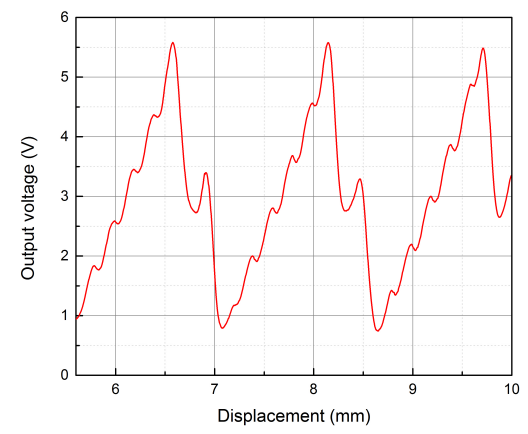

Fig. 16. Output voltage as a function of the grating in translation of $0.1 \mathrm{~mm} / \mathrm{s}$ and in rotation at $0.5 \mathrm{rps}$.

It is observed from Figure 16, the appearance of periodic peaks, when there is a rotational mouvement, in addition to the translational one. Every peak has an approximate amplitude of $1.37 \mu \mathrm{m}$, with a period of $2 \mathrm{~s}$. These periodic peaks are due to a problem of unbalanced rotation of the spindle. On the other hand, higher values for the translation and rotation speeds have been tested, Figure 17 presents the signal obained while translating at $0.5 \mathrm{~mm} / \mathrm{s}$ and rotating at $1 \mathrm{rps}$.

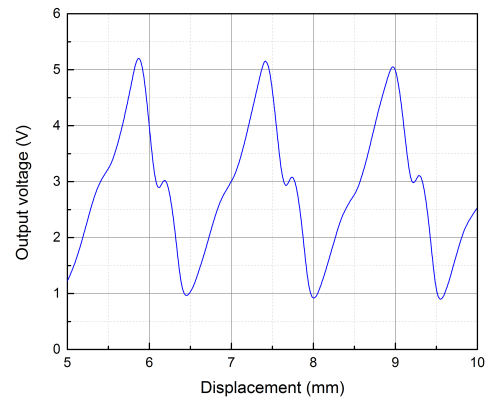

Fig. 17. Output voltage as a function of the grating in translation at $0.5 \mathrm{~mm} / \mathrm{s}$ and in rotation at $1 \mathrm{rps}$.

As observed from figure 17, with higher values for the translation and rotation speeds, the amplitudes of the peaks were attenuated. This phenomenon had been tested with each mouvement (rotation and translation) separately, where it was found out that higher values of the speed in each case attenuate the peak amplitudes in the signal.

\section{CONCLUSION \& PERSPECTIVES}

This paper presents the design of an original fiber-optic displacement sensor, used for the linear displacement measurement of a rotating spindle. First, the geometric parameters which size the cones assembled grating were defined. Then, a high precision turning machine with a single crystal diamond tool were used to fabricate ten steps of an initial prototype for the conical grating. The geometric and the surface characteristics of those steps were characterized using a Nanofocus ${ }^{\mathrm{TM}}$ uscan optical profilometer and an interferometric microscope New View 200, respectively. Good agreement with the theoretical geometric parameters was obtained as well as a nanometric roughness value. Finally, the measurement principle using one fiber-optic sensor was validated. The signal generated was duplicated and shifted in a way where a $30 \mu \mathrm{m}$ overlap was verified. In a second time, the grating was translated and rotated, simultaneously. Periodic peaks were observed in the signal output due to an unbalanced rotation of the spindle. These peaks are attenuated at higher values of the rotational and translational speeds.

In a future work, an optimized geometric model for the conical grating dimensions will be used to fabricate the final prototype, which enhances the sensor performances. The surface characteristics will be improved by decreasing the feed rate speed. In addition, two-fiber optic probes will be used to fully validate the measurement principle. For the future use of this sensor, the grating will be attached to the measurement object depending on the application used.

\section{References}

[1] P.M.B.S. Girão, O.A. Postolache, J.A.B. Faria and J.M.C.D, Pereira, An overview and a contribution to the optical measurement of linear displacement, IEEE Sens. J. 2001, pp. 322-331.

[2] K.C. Fan, Z. F. Lai, P. Wu, Y. C. Chen, Y. Chen and G. Jager. A displacement spindle in a micro/nano level, Measurement Science and Technology doi :10.1088/0957-0233/18/6/S07,2007.

[3] C.P. Chang, P.C. Tung, L.H. Shyu, Y.C. Wang, and E. Manske. FabryPerot displacement interferometer for the measuring range up to 100 mm, Measurement 46, 2013, pp. 4094-4099.

[4] S. Fourment, P. Arguel, J.-L. Noullet, F. Lozes, S. Bonnefont, G. Sarrabayrouse, Y. Jourlin, J. Jay, O. Parriaux, A silicon integrated optoelectro-mechanical displacement sensor, Sens. Actuators A 110, 2004, 294-300.

[5] A. Kimura, W. Gao, W. Kim, K. Hosono, Y. Shimizu, L. Shi, L. Zeng. A sub-nanometric three-axis surface encoder with short-period planar gratings for stage motion measuremen. Precision engineering 36, 2012, (pp. 576-585)

[6] Koegl, R.A.A.; Hogle, R.A. Real-Time. Magnetic-Flux Breakthrough Detection Method and System for Laser Drilling. U.S. Patent 5,013,886, May 1991.

[7] Koegl, R.A.A.; Hogle, R.A.; Bauer, S.D. Inductive Depth Sensing and Controlling Method and System for Laser Drilling. U.S. Patent 5,059,761, October 1991.

[8] C.-H. Lin, R. A Powell, L. Jiang, H. Xiao, S.-J. Chen and Hai-Lung Tsai. Real-time depth measurement for micro-holes drilled by lasers, Meas. Sci. Technol. 21 (2010) 025307 (6pp).

[9] C.-C. Ho, J.-J. He and T.-Y. Liao, On-Line Estimation of Laser-Drilled Hole Depth Using a Machine Vision Method, Sensors 2012, 12, 1014810162; doi: $10.3390 /$ s120810148.

[10] Z. El Rawashdeh, F. Lamarque, C. Prelle, P.Revel. Influence of the grating of cones shape on the performances of fiber-optic linear displacement sensor, Mecatronics-REM 2012 November 21-23, 2012, Paris, France.

[11] C. Prelle, F. Lamarque and P.Revel. Reflective optical sensor for long range and high resolution displacements, Sensors and Actuators, 2006, pp. 139-146.

[12] A. Khiat, F. Lamarque, C. Prelle, Ph. Pouille, M. Leester-Schadel and S. Büttgenbach "Two-dimension fiber optic sensor for high-resolution and long range linear measurements", Sensors and Actuators A, vol. 158, Issue 1, pp. 43-50, March 2010.

[13] Y. Alayli, D. Wang, M. Bonis, 1998. Optical fiber profilometer with submicronic accuracy. Proc. SPIE, 3509.

[14] A. Gautier, H. Khanfir, P. Revel, R.Y. Fillit, 2008. Polish-miror finish surfaces obtained by high precision turning, Int. J. Machining and Machinability of Materials, Vol. 4, Nos. 2/3.

[15] Z.J. Yuan, M. Zhou, S. Dong, 1996. Effect of diamond tool sharpness on minimum cutting thickness in ultraprecision machining, J. Mater. Proc. Tech. 62 (4), pp. 327-330. 